\title{
Nikkei, huáqiáo, zainichi... Enseñar una geografía de las migraciones en Asia Oriental desde la innovación docente
}

Miguel García Martín

Universidad de Sevilla

Departamento de Geografía Humana

mgmartin@us.es

ORCID: https://orcid.org/0000-0002-3318-4884

D.O.I.: http://dx.doi.org/10.12795/JDU.2018.i01.15

Pp.: 263-281

\section{Resumen}

Como parte de un proceso continuo de innovación en el ámbito educativo universitario, esta contribución recoge los aspectos esenciales de un Ciclo de Mejora Docente (CMD) aplicado a la asignatura Turismo y Flujos Migratorios en Asia Oriental. Dicho ciclo se inspira en los principios didácticos que centran el aprendizaje en el alumno, por medio de tres fases: diseño, aplicación y evaluación. La articulación las materias mediante mapas de contenidos y preguntas de investigación; la identificación y distinción entre modelos didácticos reales, ideales y posibles; así como la evaluación de los avances y las barreras cognoscitivas del alumnado mediante escaleras de aprendizaje constituyen algunas de las principales herramientas del ciclo de mejora. Los resultados obtenidos arrojan un balance positivo, que ayudará a otros 
profesores ante el desafío de cambiar nuestra práctica docente para beneficio propio, del alumnado y de la propia institución universitaria.

Palabras clave: Turismo y Flujos Migratorios en Asia Oriental, Estudios de Asia Oriental, Geografía de la Población, docencia universitaria, experimentación docente universitaria.

\section{Contexto educativo}

En el contexto del Programa de Formación e Innovación Docente del Profesorado de la Universidad de Sevilla, se presenta una experiencia de innovación docente que se ha llevado a cabo en la asignatura Turismo y Flujos Migratorios en Asia Oriental, correspondiente al Grado en Estudios de Asia Oriental (GEAO).

La clase está compuesta de unos 40 estudiantes, con una asistencia elevada (aunque nunca completa), lo que se antoja un tamaño bastante adecuado para poder hacer un mínimo seguimiento personalizado de cada alumno/a. sin embargo, las sesiones son de 2 horas, lo que obliga a diversificar las actividades en el aula y a proponer metodologías muy basadas en el trabajo de y entre estudiantes (no tanto en la transmisión unidireccional del profesor)

Los alumnos, con un alto grado de motivación dada la especialización de esta titulación, parecen mostrar una formación previa bastante satisfactoria. Como he tenido ocasión de comprobar, son estudiantes que disfrutan de su formación y se involucran profundamente en todo aquello que esté relacionado con la cultura oriental.

Si bien es la primera vez que imparto esta docencia, con lo que al proceso de mejora se le une otro previo de iniciación, de construcción desde cero-, utilizo parte de los resultados de mi experiencia de innovación docente del año pasado (recogidos en García Martín, 2017). Aunque cambia el escenario, no sucede así con la metodología de innovación, igualmente basada en diseño, implantación y 
evaluación de Ciclos de Mejora Docente (CMD), orientados a partir de los siguientes principios didácticos:

- Un aprendizaje que parte del alumno/a, que es quien reinterpreta los conocimientos a partir de sus ideas previas (aprendizaje significativo). Es lo que Bain (2007) denomina educación "centrada en el estudiante", en lugar de la "educación centrada en la disciplina" o en el "profesor".

- La conveniencia de organizar y jerarquizar los contenidos, desde los más relevantes y estructuradores hasta los más superficiales o anecdóticos. Ante la imposibilidad de poder "abordarlo todo", conviene ser pragmático y centrar el esfuerzo docente en lo más relevante.

- Partiendo de la anterior jerarquización, se debe poner el énfasis en articular los conocimientos a partir de preguntas o problemas-clave. La capacidad para saber hacerse (adecuadas y oportunas) preguntas es tan relevante como la posibilidad de poder responderlas.

- Usar un sistema de evaluación como las escaleras de aprendizaje sirve para conocer el punto de partida de los alumnos, el desarrollo efectivo de su proceso de aprendizaje - detectando "trampolines" y "barreras" de aprendizaje- y el alcance efectivo del proceso de enseñanza por parte del docente.

Este ciclo de mejora se ha organizado a partir de tres etapas fundamentales en todo proceso de mejora docente como son el diseño, la aplicación y la posterior evaluación de resultados, lo que se detalla en los siguientes epígrafes.

\section{Diseño del Ciclo de Mejora Docente}

La fase del diseño del CMD comprende la elaboración de un mapa de contenidos y problemas clave, el modelo metodológico ideal-posible con la secuencia de 
actividades previstas y un doble cuestionario (inicial y final) que sirva para observar la evolución en el proceso de aprendizaje del alumnado.

\section{Mapa de contenidos y problemas clave}

La figura 1 muestra el mapa de contenidos de la parte de la asignatura que se va a someter al ciclo de mejora. Mediante esta organización de los contenidos se pretende dar respuesta a las siguientes preguntas-problemas-casos. Estas mismas preguntas constituyen la prueba de conocimientos previos y posteriores con la que elaborar la escalera de aprendizaje que servirá para evaluar dicho proceso en el alumnado:

1. ¿Cuáles son los desafíos demográficos a los que se enfrenta Asia Oriental?

2. ¿Cuáles son los principales movimientos internos (dentro de las fronteras) en los países de Asia Oriental? ¿Qué consecuencias han tenido?

3. ¿Dónde se encuentran las principales comunidades de asiáticos orientales a lo largo del mundo (las diásporas)?

4. ¿Qué oportunidades y problemas plantean los inmigrantes que se desplazan hacia los países de Asia Oriental?

Jornadas de Formación e Innovación Docente del Profesorado | № 1 (2018) Esta obra se distribuye con la licencia Creative Commons 
MAPA DE CONTENIDOS: FLUJOS MIGRATORIOS EN ASIA ORIENTAL

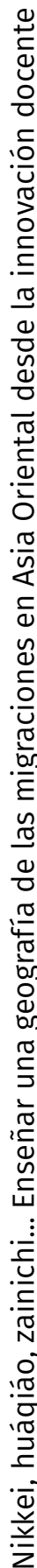

Figura 1. Mapa de contenidos y problemas clave (MCP) tenidos en los que prevalecen las competencias procedicompetencias actitudinales. He optado por una fórmula que no sea tan reduccionista, puesto que a veces tengo la sensación de que la forma en que clasificamos los contenidos (conceptuales, procedimentales y actitudinales) es cimiento poblacional, que es un problema demográfico se-

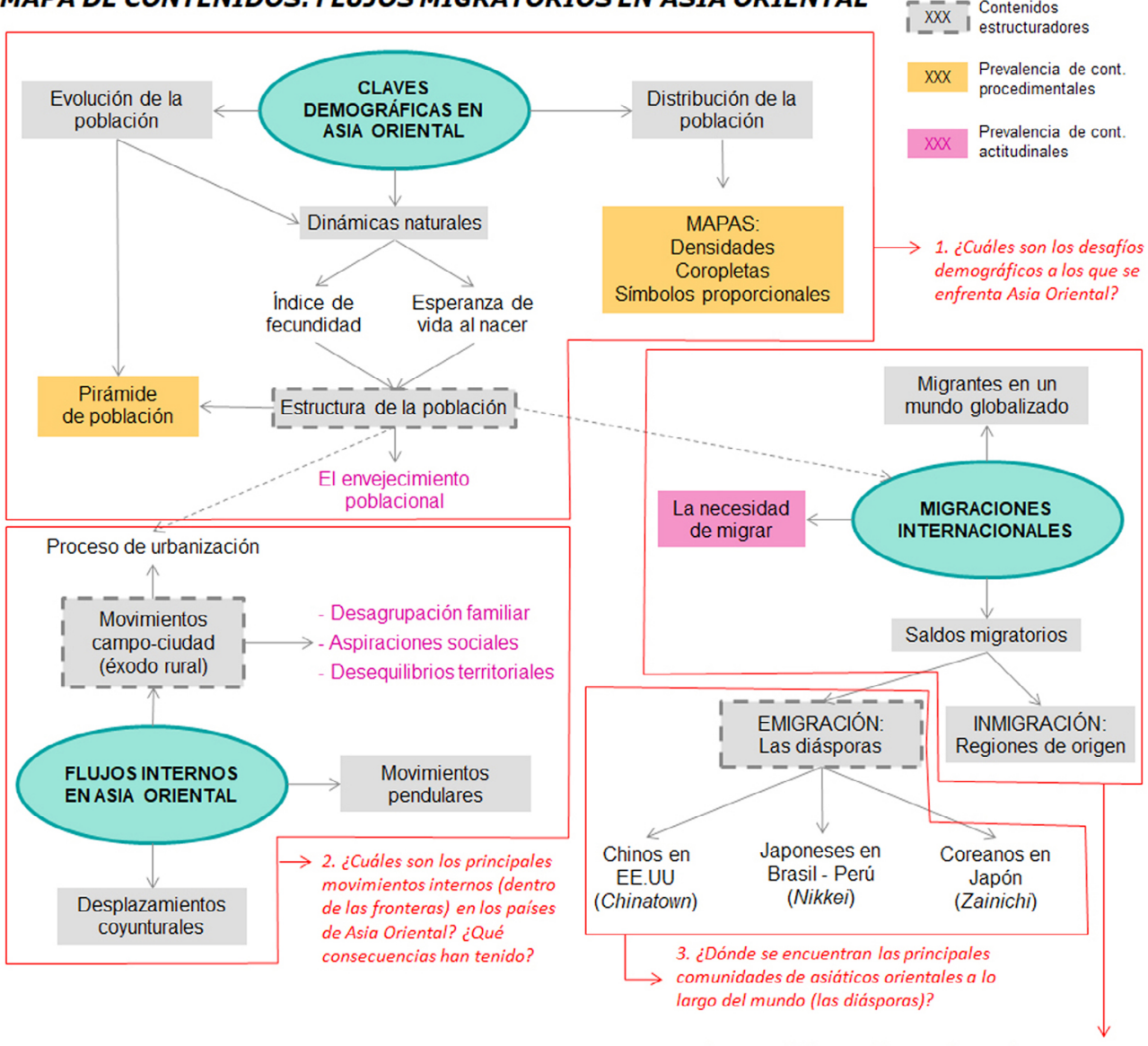

4. ¿Qué oportunidades y problemas plantean los inmigrantes que se desplazan hacia los países de Asia Oriental?

Como puede observarse en el anterior mapa, hay conmentales y otros en los que resultan muy relevantes las demasiado excluyente. Tomando como ejemplo el envejerio en Corea o Japón, este debería abordarse desde esa 
óptica actitudinal (el tema de las pensiones, el dilema inmigratorio, el papel de las máquinas...), pero irremediablemente, al enfrentarnos a estos conceptos, también se enseñan procedimientos y herramientas de análisis para evaluar e identificar el envejecimiento

\section{Modelo metodológico posible y secuencia de actividades}

Este ciclo de mejora comprende un total de 10 horas, repartidas en 5 sesiones. El CMD aborda el tema 5 (Procesos de migración internos y distribución de la población) y parte del tema 6 (Migraciones internacionales: diáspora china y otros flujos demográficos).

En el modelo metodológico tradicional o habitual, la impartición de contenidos conceptuales esencialmente teóricos, tipo clases magistrales, organizan la mayor parte de las sesiones. Para ello, predomina el uso de diapositivas que, de forma secuencial y lineal, sirven de hilo conductor a un discurso transmisor de conocimientos. Las diapositivas suelen contener gráficos, esquemas y mapas que sirven para construir los conocimientos, por medio del análisis inferencial y la propia exposición de evidencias.

El modelo metodológico ideal o idílico debe partir de los conocimientos previos de los alumnos, especialmente en una titulación donde los alumnos se sienten profundamente atraídos por la cultura oriental, lo que favorece el que exista un bagaje de conocimientos ya adquiridos, pero donde también se alimentan ciertas preconcepciones y estereotipos. Y es que los estudiantes, en tanto que seres epistémicos, producen y reproducen ideas que deben ser objeto de debate y negociación crítica (Alba y Porlán, 2017).

A cada establecimiento de un conocimiento o punto de partida (hipótesis del alumno) le corresponde una actividad que sirva para reforzar positivamente dicho punto o para rechazarlo. Dado que este ejercicio de refutación deberían hacerlo los propios alumnos por sus medios 
(aprendizaje significativo), la posterior tarea del profesor es poner orden (organizar) esas conclusiones o contrastes, darles una forma coherente a aquello a lo que han llegado los alumnos de forma dispersa, aislada y desestructurada. Una tarea final de tipo práctico puede servir para reforzar más si cabe estos conceptos y para lanzar la siguiente "iteración", es decir, el siguiente punto de partida.

Por último, el modelo metodológico posible (figura 2) no es más que una adaptación del anterior modelo ideal a las coyunturas y limitaciones propias del contexto educativo (y, por qué no, de mis propias limitaciones procedimentales). En dicho modelo se procura incentivar la curiosidad por una temática concreta mediante actividades previas (como por ejemplo una película) o lecturas fuera de las sesiones presenciales. Estas actividades previas sirven como marco que introduce las preguntas de investigación, que no son más que incógnitas y cuestiones que propone el profesor, que surgen al calor del visionado o la lectura del recurso propuesto. En una segunda sesión posterior se abordan estas mismas preguntas por medio de un taller conceptual, siguiendo el método de hojas de actividades propuesto por Finkel (2008). Se trabajan en grupo varias preguntas encadenadas, con la posibilidad de consultar bases de datos online y otras fuentes estadisticas y documentales.
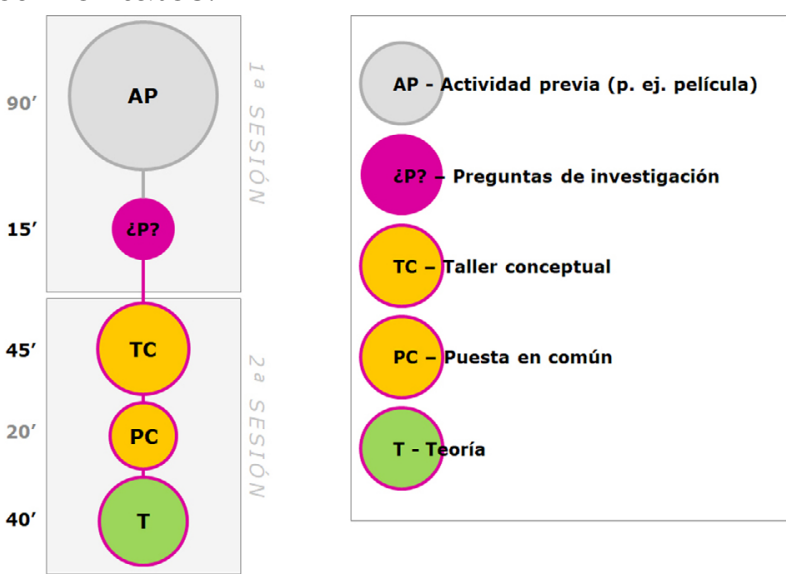

Figura 2. Modelo metodológico posible

Jornadas de Formación e Innovación Docente del Profesorado I № 1 (2018)
Esta obra se distribuye con la licencia Creative Commons Reconocimiento-NoComercial-SinObraDerivada Internacional (CC BY-NC-ND 4.0.) 
Una vez resueltos estos talleres conceptuales se intenta poner en común los resultados. La doble sesión concluye con una exposición teórica que recoge las principales ideas a las que los alumnos han llegado, contrastándolas con las ideas del profesor y sirviendo como recopilación, ampliación y matización de los distintos contenidos.

A continuación se detallan secuencialmente las actividades programadas para las 5 sesiones que comprenden el CMD (Tabla 1):

Tabla 1

Secuencia de actividades del ciclo de mejora

\begin{tabular}{|c|c|c|}
\hline SESIONES & CONTENIDOS & ACTIVIDADES \\
\hline \multirow[t]{3}{*}{$\begin{array}{l}\text { Sesión } 1 \\
\text { (lunes) }\end{array}$} & $\begin{array}{l}\text { CLAVES DEMOGRÁFICAS } \\
\text { EN AO }\end{array}$ & $\begin{array}{l}\text { Distribución del cuestionario previo } \\
\text { Distribución de la 1a HOJA DE ACTIVIDADES } \\
\text { 1o Taller conceptual: Evolución y dinámicas } \\
\text { naturales de población. Los alumnos deben } \\
\text { trabajar en grupos de } 3 \text { y apoyarse en re- } \\
\text { cursos online facilitados por el profesor por } \\
\text { medio de un ordenador portátil por grupo. } \\
\text { Debate y puesta en común de las respuestas } \\
\text { y las principales conclusiones a las que han } \\
\text { llegado los grupos. }\end{array}$ \\
\hline & & Descanso \\
\hline & & $\begin{array}{l}\text { Teoría contrastada: Exposición de conteni- } \\
\text { dos contrastados con ideas y cifras plantea- } \\
\text { das por alumnos. } \\
\text { 2o- Taller conceptual: La estructura de la po- } \\
\text { blación mediante la interpretación de las pi- } \\
\text { rámides de población. } \\
\text { Debate y puesta en común. } \\
\text { Teoría contrastada. } \\
\text { 3o Taller conceptual: La distribución de la } \\
\text { población mediante el mapa. Los alumnos } \\
\text { deben empezar a diseñar distintos mapas } \\
\text { de población y entregarlos ya elaborados } \\
\text { antes de la siguiente sesión. Esta actividad } \\
\text { se presenta en clase, pero se trabaja fuera } \\
\text { del horario presencial. }\end{array}$ \\
\hline
\end{tabular}

Jornadas de Formación e Innovación Docente del Profesorado | № 1 (2018) Esta obra se distribuye con la licencia Creative Commons Reconocimiento-NoComercial-SinObraDerivada Internacional (CC BY-NC-ND 4.0.) 


\begin{tabular}{|c|c|c|}
\hline $\begin{array}{l}\text { Sesión } 2 \\
\text { (miércoles) }\end{array}$ & $\begin{array}{l}\text { CLAVES } \\
\text { DEMOGRÁFICAS EN AO } \\
\text { FLUJOS INTERNOS EN AO }\end{array}$ & $\begin{array}{l}\text { Preguntas de investigación: ¿Cuáles son } \\
\text { las fórmulas o métodos que resultan más } \\
\text { ilustrativos para localizar las grandes áreas } \\
\text { pobladas? } \\
\text { Teoría contrastada: Se exponen algunos } \\
\text { ejemplos de mapas ya elaborados, compa- } \\
\text { rándolos con los realizados por los alumnos. } \\
\text { Se compara cuál es la mejor técnica para se- } \\
\text { gún qué propósitos. }\end{array}$ \\
\hline & & Descanso \\
\hline & & $\begin{array}{l}\text { Visionado de la película Last Train Home. (La } \\
\text { película dura aprox. } 85 \text { minutos, los alum- } \\
\text { nos tienen que terminar de ver el documen- } \\
\text { tal en casa). } \\
\text { Preguntas de investigación: Sobre los mo- } \\
\text { vimientos campo-ciudad (éxodo rural), que } \\
\text { subyacen en el documental y el texto com- } \\
\text { plementario "China lanza una masiva cam- } \\
\text { paña de migración del campo a la ciudad (El } \\
\text { País)". Estas preguntas se abordarán en la si- } \\
\text { guiente sesión, con lo que deben ser traba- } \\
\text { jadas fuera del horario presencial. }\end{array}$ \\
\hline \multirow[t]{3}{*}{$\begin{array}{l}\text { Sesión } 3 \\
\text { (lunes) }\end{array}$} & $\begin{array}{l}\text { FLUJOS } \\
\text { INTERNOS EN AO }\end{array}$ & $\begin{array}{l}\text { Distribución de la 2a HOJA DE ACTIVIDADES } \\
\text { 10 Taller conceptual: Población urbana vs. } \\
\text { población rural (proceso de urbanización). } \\
\text { Debate y puesta en común. } \\
\text { Teoría contrastada. }\end{array}$ \\
\hline & & Descanso \\
\hline & & $\begin{array}{l}\text { 2o- Taller conceptual: los flujos campo-ciu- } \\
\text { dad y otros flujos internos. } \\
\text { Debate y puesta en común. } \\
\text { Teoría contrastada. }\end{array}$ \\
\hline
\end{tabular}




\begin{tabular}{|c|c|c|}
\hline $\begin{array}{l}\text { Sesión } 4 \\
\text { (miércoles) }\end{array}$ & $\begin{array}{l}\text { MIGRACIONES INTER- } \\
\text { NACIONALES EN AO }\end{array}$ & $\begin{array}{l}\text { Preguntas de investigación: Sobre los mo- } \\
\text { vimientos migratorios internacionales. Para } \\
\text { ello, se recurren a ciertas imágenes, notas } \\
\text { de prensa y otras fuentes en medios de co- } \\
\text { municación que alimentan estas preguntas. } \\
\text { Visionado de la película El club de la buena } \\
\text { estrella. A lo largo del visionado se inte- } \\
\text { rrumpe la película para introducir nuevas } \\
\text { preguntas e interrogantes que los alum- } \\
\text { nos deberán resolver fuera del horario } \\
\text { presencial. } \\
\text { Antes de acabar, se presenta el texto com- } \\
\text { plementario "El Atlas de las Migraciones" de } \\
\text { cara a su trabajo en la siguiente sesión. }\end{array}$ \\
\hline \multirow[t]{3}{*}{$\begin{array}{l}\text { Sesión } 5 \\
\text { (lunes) }\end{array}$} & $\begin{array}{l}\text { MIGRACIONES INTER-NA- } \\
\text { CIONALES EN AO }\end{array}$ & $\begin{array}{l}\text { Distribución de la 3a HOJA DE ACTIVIDADES } \\
\text { 1o Taller conceptual: la migración como fe- } \\
\text { nómeno global y las necesidades de migrar. } \\
\text { Debate y puesta en común. } \\
\text { Teoría contrastada. }\end{array}$ \\
\hline & & Descanso \\
\hline & & $\begin{array}{l}\text { 2o Taller conceptual: saldos migratorios, } \\
\text { principales diásporas y problemas de las co- } \\
\text { munidades foráneas en los países de AO. } \\
\text { Las preguntas están muy vinculadas con la } \\
\text { película y el texto trabajados en la sesión } \\
\text { anterior. } \\
\text { Debate y puesta en común. } \\
\text { Teoría contrastada. } \\
\text { Distribución del cuestionario posterior. }\end{array}$ \\
\hline
\end{tabular}

\section{Aplicación del Ciclo de Mejora Docente}

\section{Relato resumido de las sesiones}

En la primera sesión les introduzco el método basado en talleres conceptuales y hojas de actividades, que servirán como hilo conductor de los contenidos que se vayan abordando. Parecen algo desconcertados ante lo que tiene que hacer, hasta el punto de que casi todos preguntan con incredulidad si las hojas de actividades se "entrega" al final de la clase. 
En la segunda sesión todavía percibo cierta falta de compromiso y dinámica en los grupos. Solo unos pocos parecen entender la mecánica basada en el establecimiento de diálogos abiertos que guían la secuencia de preguntas-respuestas. Me comprometo a involucrar al resto de la clase en las próximas sesiones, dado que las hojas de actividades funcionan bien con unos cuantos, pero pierdo el control de aquellos que muestran menos estímulos.

En la tercera sesión percibo que los alumnos empiezan a familiarizarse con el método de las hojas de actividades. Contrasto sus comentarios con mis argumentos, lo que les mantiene activos si mi argumentación no se prolonga demasiado tiempo. Son más participativos cuando las preguntas se mantienen en el aire, no cuando las cierro con evidencias y datos proyectados en las diapositivas. Si bien no todos los alumnos participan en las puestas en común, las respuestas de los que lo hacen suelen estar muy bien encaminadas, lo que implica a) que creo que las he formulado adecuadamente y b) que están siendo provechosas en el proceso de aprendizaje por estímulos.

La cuarta sesión está condicionada por ser víspera de festivo, lo que se refleja en la baja asistencia y menor motivación, circunstancia que me desquicia un poco. Por si fuera poco, les señalo que tienen que consultar unas hojas en Excel y procesar algunas cifras, tras lo cual descubro con asombro que hay bastantes alumnos que no se sienten capacitados para manejar herramientas informáticas que consideraba elementales.

La quinta sesión se desarrolla en el aula de informática, precisamente porque estimo esencial que sepan consultar ciertas fuentes estadísticas disponibles online. Aprecio cierta motivación e interés al cambiar el escenario físico. Muestran dificultades en el manejo de Excel, por lo que la sesión se ralentiza más de la cuenta. Salvo una minoría de alumnos que - dado que tienen soltura con esta herramienta informática- captan las actividades de investigación al momento, la mayoría se sienten abrumados 
ante la dificultad técnica (si bien comprenden perfectamente la finalidad).

\section{Evaluación del aprendizaje de los estudiantes: las Escaleras de Aprendizaje}

Mediante cuestionarios de evaluación aplicados antes y después del CMD se puede observar el progreso experimentado en los alumnos. Las respuestas del cuestionario final se contrastan con las del cuestionario inicial mediante la categorización de las respuestas individuales en grupos similares (cajones). Cada una de las categorías supone un nivel de aprendizaje y sus límites marcan dificultades o superaciones en ese proceso educativo (Rivero y Porlán, 2017). Las siguientes figuras muestran, mediante escaleras de aprendizaje, el balance entre ambos momentos, cuando se observa la diferencia de respuestas en una u otra categoría (lo que se indica con los porcentajes Pre y Post). El diagrama inferior derecho funciona como histograma comparativo entre ambos momentos (momento previo en amarillo y momento posterior en azul), lo que permite reconocer visualmente si ha habido un "transvase" desde las categorías inferiores a las superiores.

En la primera pregunta (Figura 3) se puede observar que los conocimientos de partida de los alumnos son significativos, habida cuenta del alto porcentaje de respuestas iniciales que ya mencionan el envejecimiento como factor demográfico clave. Las mejoras que experimenta la clase son discretas, aunque de signo positivo (tras el CMD no hay alumnos en el nivel 0 , y aumentan las respuestas en el nivel 4, el de mayor complejidad). Más allá de esta mejoría leve, sí se ha percibido una forma de argumentar algo más elaborada, con el uso de un vocabulario más preciso y una distinción en muchos casos entre los desafíos demográficos de China, por un lado, y los de Corea de Sur y Japón, por otro. 


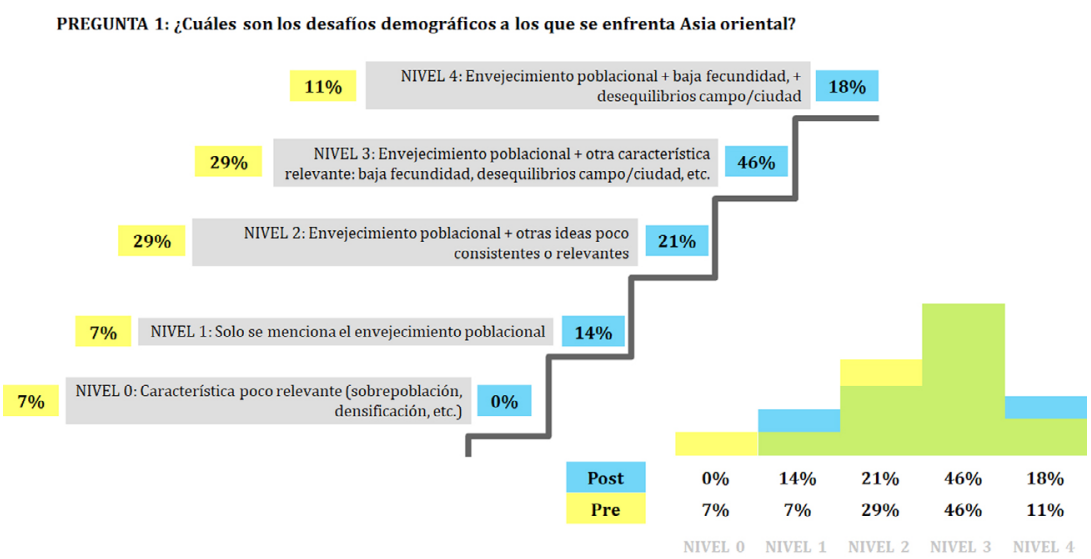

Figura 3. Escalera de aprendizaje de la primera pregunta

En la segunda pregunta (Figura 4) se pone de manifiesto una mejora considerable en la asimilación de los contenidos estructuradores: se observa un "desplazamiento" generalizado de las respuestas hacia las categorías más complejas y ricas. Tras las sesiones de clase, un $80 \%$ aproximado del alumnado ha podido indicar algún movimiento interno relevante, en especial el movimiento campo-ciudad. Hasta entonces, tan solo un $36 \%$ de la clase reconocía este fenómeno. Los movimientos pendulares (commuting), que no parecían reconocerse en las respuestas iniciales, también son descritos por algunos estudiantes.

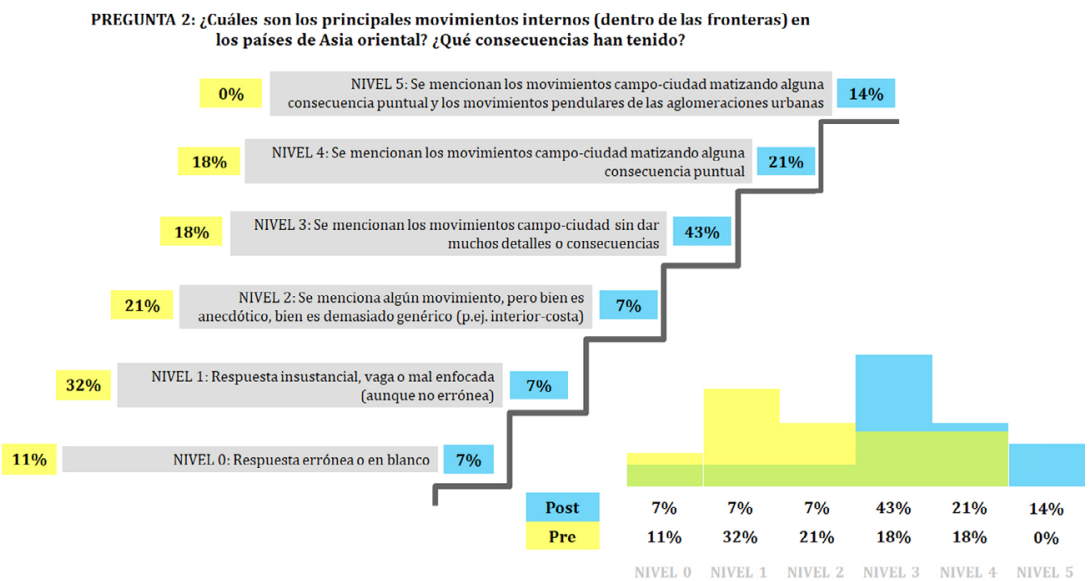

Figura 4. Escalera de aprendizaje de la segunda pregunta

Jornadas de Formación e Innovación Docente del Profesorado | № 1 (2018)

(C) Esta obra se distribuye con la licencia Creative Commons Reconocimiento-NoComercial-SinObraDerivada

Internacional (CC BY-NC-ND 4.0.) 
En la tercera pregunta (Figura 5), igualmente, se observa una mejoría destacable. En los test previos, es llamativo que cerca de la mitad de las respuestas presentan una orientación plausible: el $43 \%$ de la muestra aporta una respuesta categorizada en el nivel 2 (Se mencionan los EE.UU y algunas otras regiones de forma genérica). Esto nos da una idea del relativamente avanzado nivel de partida del alumnado. Sin embargo, también se detectan respuestas poco consistentes o "flojas", sin ser ninguna de ellas erróneas. De todas las preguntas, esta era la que tenía una formulación más sencilla, solo había que mencionar regiones a lo largo del mundo. Las respuestas de los test posteriores arrojan lecturas interesantes. De un lado, muy pocos alumnos siguen ofreciendo un conocimiento vago (nivel 0 ). Por otro lado, surgen dos niveles de respuesta que no se habían dado con anterioridad: o bien se mencionan a grandes rasgos las principales regiones de destino -con EE.UU. a la cabeza- o bien se hace una distinción pormenorizada entre las diásporas chinas, coreanas y japonesas, lo que supone un nivel de comprensión del fenómeno complejo y elaborado.

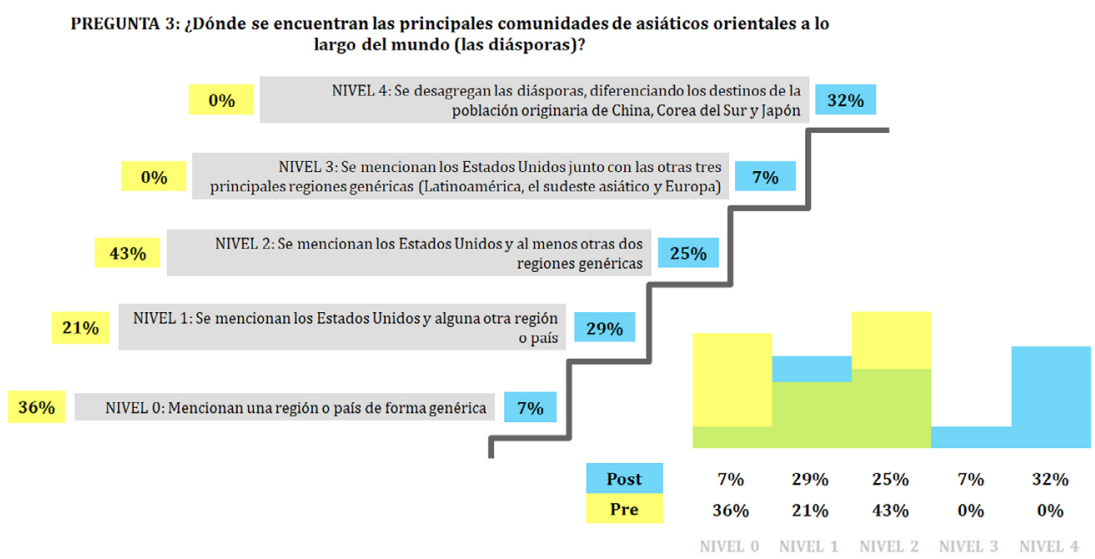

Figura 5. Escalera de aprendizaje de la tercera pregunta

En la cuarta y última pregunta (Figura 6) se puede observar un desplazamiento generalizado hacia la derecha de la gráfica, esto es, hacia las respuestas más ricas y 
complejas. La mayor parte de los alumnos han aportado argumentos considerados esenciales en los desafíos inmigratorios de los países de AO. Es más, un tercio aproximado de ellos ha basado su respuesta en el establecimiento comparativo entre las oportunidades y los problemas, como hechos entrelazados y no como cuestiones aisladas, lo que supone un nivel avanzado en la adquisición del aprendizaje. Los alumnos que ofrecen respuestas “simples" son ahora una minoría residual.

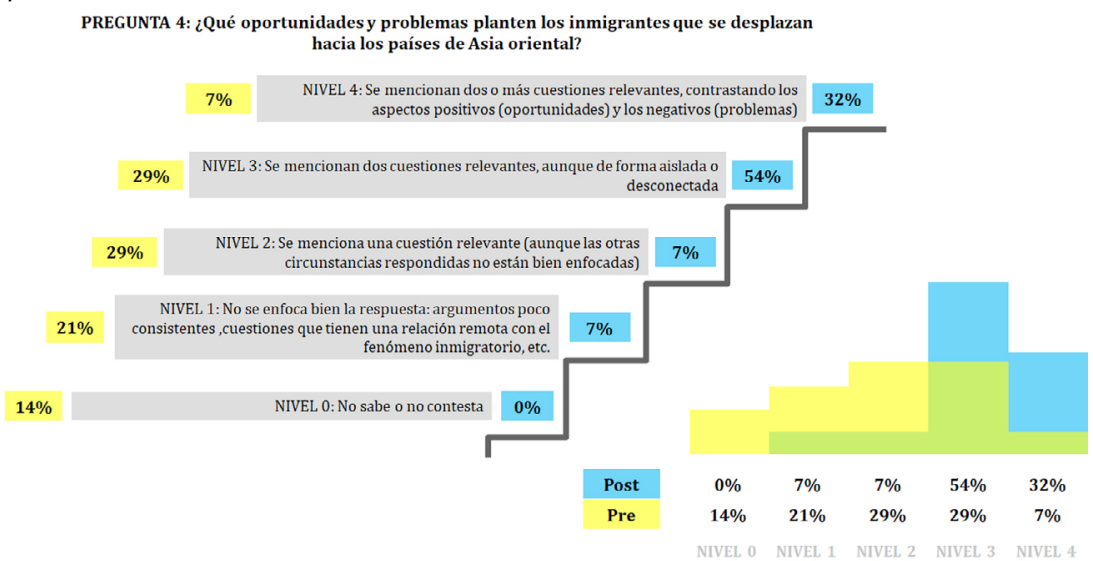

Figura 6. Escalera de aprendizaje de la cuarta y última pregunta

\section{Evaluación del Ciclo de Mejora Docente}

\section{Cuestiones a mantener, a incorporar y a mejorar en futuros ciclos de mejora}

A modo de valoración positiva de esta experiencia sobresale, ante todo, el taller metodológico (en su aspecto esencial) como herramienta que guía la impartición de las sesiones. Estos talleres, organizados por medio de hojas de actividades, favorecen el trabajo en grupo y la actitud dinámica y proactiva del alumnado. Los alumnos van poco a poco abordando distintas cuestiones conceptuales, instrumentales y de pensamiento crítico, tras lo cual el

Jornadas de Formación e Innovación Docente del Profesorado | № 1 (2018)

Esta obra se distribuye con la licencia Creative Commons Reconocimiento-NoComercial-SinObraDerivada Internacional (CC BY-NC-ND 4.0.) 
profesor tan solo debe reorganizar la forma en que ellos han abordado las cuestiones.

Muy en la línea de lo anterior, también se consolida ante futuros ciclos de mejora la utilización de la sintaxis interrogativa como eje en la comunicación profesor-alumno, es decir, abordar los contenidos por la vía de las preguntas, no de las respuestas. Formular una incertidumbre es intelectual y cognitivamente mucho más estimulante que ofrecer una respuesta ya resuelta.

De cara al futuro, se puede ampliar el mapa de contenidos con el estudio de la comunidad inmigrante china en España y particularmente en Sevilla, a partir de un aprendizaje basado en proyectos. Como continuación lógica, se abordarían los contenidos mediante un enfoque empírico con encuestas y otras herramientas de investigación. Otro aspecto a incorporar es la sustitución sucesiva de los mecanismos de evaluación basados en el examen por otros en los que exista la posibilidad de generar retroalimentaciones (feedback) que puedan volver a ser evaluadas. En esta experiencia he podido observar que los alumnos tienen un grado muy alto de compromiso con las actividades cuando son susceptibles de calificación, no así al contrario. Utilizar pequeños estímulos en forma de recompensas hace que el alumnado colabore y se comprometa activamente en su propio aprendizaje.

A pesar de las sensaciones por lo general positivas tras la aplicación del CMD, quedan algunos puntos negros que deberán ser corregidos de cara a experiencias de mejora futuras. Por un lado, las hojas de actividades funcionan bien cuando el alumnado está motivado y muestra una actitud proactiva de partida. Pero han existido casos en los que los estudiantes no terminaban de comprender el objetivo de dicha herramienta. Con el sintomático comentario del tipo "¿esto se entrega?", algunos estudiantes mostraban desconcierto ante esta forma de funcionar. Probablemente tienen asimiladas estructuras didácticas clásicas y convencionales, en las que esperan una clase magistral por transmisión. De cara al futuro, hay que articular mecanismos para "enganchar" a esta parte del alumnado, 
con fórmulas como la obligación de exponer las respuestas mediante puesta en común, ofrecer micro-bonificaciones, etc.

\section{Incorporaciones a la práctica docente habitual}

Por último, a partir de los principios didácticos que inspiran esta experiencia, se pueden plantear incorporaciones a la práctica docente habitual, fruto de las sensaciones positivas generalizadas que se van acumulando tras varios ciclos de mejora.

La clave de este cambio de modelo didáctico se basa en la idea, presente a lo largo de estas semanas sometidas a innovación, de que es el alumno el que aprende, no el profesor el que enseña. Son los alumnos los que deben construir su aprendizaje a partir de la elaboración de nuevas ideas (conceptos, procedimientos y actitudes) que surgen de las ya existentes. Eso se traduce en el uso de una parte muy importante del tiempo de las sesiones presenciales para que sean ellos los que proyecten esas ideas, mediante debates, ejercicios de contraste de hipótesis, actividades colectivas, juegos de rol, preguntas encadenadas, etc.

El otro pilar fundamental de los principios didácticos es la conveniencia de tener un esquema de contenidos bien estructurado, sustentado en preguntas-interrogantes-cuestiones que ofrezcan al alumnado el estimulo necesario para producir esa "pulsión cognitiva" que está en la base de todo deseo de aprender. Rescatando el clásico proverbio aristotélico por el cual el ignorante afirma; el sabio duda y reflexiona, en mis futuras clases habré de formular y fomentar las preguntas adecuadas que guien el camino hacia la revelación de los contenidos planteados. Al fin y al cabo, sin preguntas (o con preguntas mal formuladas), la consecución de los objetivos de aprendizaje se antoja una tarea estéril.

Jornadas de Formación e Innovación Docente del Profesorado I № 1 (2018) Esta obra se distribuye con la licencia Creative Commons 


\section{Referencias bibliográficas}

Alba, N. y Porlán, R. (2017). La metodología de enseñanza. En Porlán, R. (Coord.). Enseñanza universitaria. Cómo mejorarla (pp. 37-53). Madrid: Morata.

Bain, K (2007). Lo que hacen los mejores profesores universitarios. Valencia: Publicacions de la Universitat de València

Finkel, D. (2008). Dar clase con la boca cerrada. Valencia: Publicacions de la Universitat de València.

García Martín, M. (2017). Innovación docente en Geografía: del yo te enseño al tú me enseñas cómo aprendes. En Porlán Ariza, R. y Navarro Medina, E. (Cords.). Jornadas de Formación e Innovación Docente. Universidad de Sevilla (4 y 5 de diciembre de 2017) (pp. 1038-1051). Sevilla: Secretariado de Formación y Evaluación, Universidad de Sevilla.

Ribero, A. y Porlán, R. (2017). La evaluación en la enseñanza universitaria. En Porlán, R. (Coord.). Enseñanza universitaria. Cómo mejorarla (pp. 73-91). Madrid: Morata.

Jornadas de Formación e Innovación Docente del Profesorado | № 1 (2018) Esta obra se distribuye con la licencia Creative Commons 
Jornadas de Formación e Innovación Docente del Profesorado | № 1 (2018) (c) (i) $(2)$ Esta obra se distribuye con la licencia Creative Commons Reconocimiento-NoComercial-SinObraDerivada $\quad 4.0$ Internacional (CC BY-NC-ND 4.0.) 